\title{
Gente de palabras. Subjetividades indígenas en transformación en el Chiapas contemporáneo ${ }^{1}$
}

\author{
Words People. Indigenous Subjedctivities \\ in Transformation in Contemporary Chiapas
}

\author{
Isabel Neila Boyer \\ Facultad de Filosofía \\ Universidad Nacional de Educación a Distancia —UNED—, España
}

\section{RESUMEN}

A partir de un análisis de la concepción y uso de las palabras entre tzeltales y tzotziles de la región de Los Altos de Chiapas, el presente artículo discute cómo en el "nuevo vivir" tzotzil, ach kuxlejal, el interpretado uso incompetente del lenguaje como efecto de la 'modernidad' ha derivado en una percepción de otra humanidad y en un cuestionamiento sobre la identidad indígena de la juventud; a quienes tildan como "los del nuevo crecimiento" (ach' chieletik) o "los del nuevo vivir" (ach' kuxlejaletik).

Palabras clave: Chiapas; Modernidad; Subjetividades indígenas.

\section{SUMMARY}

From an analysis of the design and use of words between tzeltal and tzotzil indigenous of the region Los Altos de Chiapas, this article discusses how the "new life" tzotzil, ach kuxlejal, the interpreted incompetent use of language as effect of 'modernity' has led to a perception of another humanity and a questioning of indigenous identity of youth; those branded as "the new growth" (ach 'chieletik) or "the new life" (ach' kuxlejaletik).

Key words: Chiapas; Modernity; Indigenous Subjectivities.

\section{A MODO DE INTRODUCCIÓN: GÉNESIS Y PALABRAS}

Según la concepción tzotzil y tzeltal, compartida por otros grupos mayas, la palabra —o las palabras, mejor dicho— son mucho más que un vehículo de expresión y

\footnotetext{
${ }^{1}$ El trabajo de investigación que da pie a este artículo no hubiera sido posible sin el apoyo financiero, institucional y humano de la AECID, el CIESAS-Sureste y el IEI, a quienes debo mi gratitud.
} 
un marcador de etnicidad, son un signo de humanidad en el más amplio sentido del término ${ }^{2}$. Tanto que las palabras y el habla, al menos de una manera competente, no siempre han estado presentes en las distintas creaciones, lo que ha contribuido a la consideración de humanidades fallidas precedentes a la actual. Así por ejemplo, la evolución de edades anteriores referida por el Popol Vub pone de manifiesto cómo la gente de génesis previas si bien hablaba lo hacía de una manera ineficaz e incompetente, careciendo de entendimiento (Recinos 1999: 23-32). Ya desde entonces se concibe el habla competente como aquel que lleva implícita la idea del respeto; expresado éste en términos de gratitud, obediencia y con un lenguaje solícito que incluye la petición ritual. Desde entonces también este habla competente ha sido señal de humanidad, de tal manera que dicha idoneidad lingüística ha ido ligada, además, a otros aspectos socializadores de la persona ${ }^{3}$.

En el presente artículo me propongo reflexionar, a partir de una concepción emic de las palabras y su articulación como discursos, y a la luz de la emergencia de novedosas retóricas con la 'modernidad', precisamente sobre la construcción de nuevas subjetividades e identidades indígenas en el contexto chiapaneco y, específicamente, entre la población tzotzil y tzeltal. Una de las cuestiones que planteo es si puede, de nuevo, el considerado uso incompetente del lenguaje (desde una perspectiva nativa) conducir no sólo a una percepción diferencial de las nuevas generaciones en términos de subjetividad e identidad sino, incluso, y como parece ser el caso, sostener en base a ello la afirmación de que otro tiempo es presente. Uno donde el inapropiado uso del lenguaje vendría a refutar la idea de que este momento le pertenece a otra gente que dicen "ya están así como kaxlanes (castellanos/mestizos)". De este modo, lo que sugiero —más allá del tradicional argumento sustentado en el inseparable binomio lengua/identidad que sostiene que un menoscabo en el idioma, o cierto grado de erosión lingüística, supone una amenaza hacia la integridad étnica y cultural- es cómo el distinto empleo de las palabras y de la lengua que hace la juventud como efecto de la 'modernidad' respecto del de sus mayores conlleva la percepción de una humanidad diferente y, por tanto, de un nuevo tiempo que han de-

\footnotetext{
${ }^{2}$ Pone de manifiesto Haviland (1984: 337) que para los tzotziles — concretamente para los zinacantecos- ser humano significa tener la capacidad de hablar y hacerlo en su lengua, el tzotzil. Afirmando, además, que el universo social inmediato es aquel en el que se puede entablar una conversación. Tal es la importancia del habla que una discapacidad en ella es entendida como un defecto mental; asimismo, cuando alguien se expresa tontamente es porque todavía es chich, ingenua e inmadura.

${ }^{3}$ En este sentido son abundantes las referencias, tanto en antiguos mitos mayas y aztecas como en diferentes contextos mesoamericanos contemporáneos, sobre la emergencia del habla a la par que la verdadera comida y el vestido. Al respecto, advierte Cámara Barbachano (1946: 34) cómo en mitos tzeltales del municipio chiapaneco de Tenejapa se refiere claramente que cuando el hombre comenzó a comer también lo hizo a hablar. Asimismo, en los Anales de los cakchiqueles se dice que "[...] cuando hicieron al hombre, de tierra lo fabricaron, y lo alimentaron de árboles, lo alimentaron de hojas. Únicamente tierra quisieron que entrara [en su formación]. Pero no hablaba, no andaba, no tenía sangre ni carne". A esta primera raza le precedió otra nueva humanidad conformada por maíz y sangre que logró el habla, la verdadera comida, la carne y la posibilidad de multiplicarse. Igualmente los mayas ch'orti' del oriente de Guatemala creen, según etnografía López García (2003: 216), que en la humanidad previa a la actual no se comía, al menos comida, ni se hablaba; tampoco había sexo ni vestido. En definitiva, en los ensayos anteriores a la humanidad actual o se carecía de palabras o se hacía mal uso de ellas.
} 
nominado ach' kuxlejal ("nuevo vivir"). Tanto es así que realmente la cuestión no es ya que la identidad indígena esté asociada al habla de una lengua concreta (asociación operativizada para efectos estadísticos y de programación de políticas públicas) cuanto que para tzotziles y tzeltales los nuevos estilos del habla alejados del considerado habla competente (moralmente correcto) son señal manifiesta de un cambio en las subjetividades e identidades indígenas, además de signo de otra era. Así, puede darse el caso, como ocurre, que incluso hablando una lengua indígena, pero haciéndolo sin tener en consideración ciertos aspectos formales que confieren a las palabras su cualidad étnica (y ética), sea señal de ladinización y viceversa. Es decir, que hablar en castellano pero haciéndolo con modo (esto es, siguiendo unas pautas culturales del habla apropiada) no implique un cuestionamiento acerca de la identidad indígena de alguien; máxime en este tiempo donde la escolarización, la migración nacional e internacional, los medios de comunicación y otros factores impelen al uso de este idioma. El argumento que defiendo en las páginas que siguen pretende, de este modo, ir más allá de la idea corriente con relación a los pueblos indígenas acerca de cómo la pérdida o el abandono de señas de identidad tales como la lengua (o el atuendo tradicional) son sintomáticos de su ladinización o mestizaje.

Aparte de esto voy a sugerir, también, cómo entre los tzotziles y tzeltales la manifestación competente o incompetente del lenguaje que, como apunto, determina en última instancia el ser indígena viene condicionada por el tipo de palabras de que está hecha (literalmente) una persona. De manera que las identidades y las subjetividades indígenas no dependen tanto de cómo y en qué forma las palabras dichas con el habla salen del cuerpo —es decir, y reitero, bajo qué lengua y de qué modo-, que también, cuanto por el tipo de palabras (y discursos) que acceden al él (y lo construyen) durante el desarrollo personal, confiriendo al sujeto las pautas de un modo de actuar propiamente indígena o, por el contrario, más ladinizado. Y es que en la concepción tzotzil y tzeltal las palabras tienen la entidad de substancia que entra, o puede hacerlo, al organismo, modificando su estado y cambiando su condición ${ }^{4}$. Al respecto, la idea que sostengo es que si bien tradicionalmente las palabras de los antiguos (las palabras de los consejos, mantal) emitidas durante las etapas de maduración personal han jugado un papel substancial (y subrayo lo de substancial) en la conformación del ser indígena y, por tanto, en la construcción de su subjetividad e identidad, ahora, en cambio, en el "nuevo vivir" ( $a c b$ ' kuxlejal) derivado de la 'modernidad' a los adultos les avergüenza aconsejar y las jóvenes generaciones se socializan en un ambiente poblado de nuevas retóricas; discursos globalizados que igualmente interiorizan y les definen o construyen, pero ya como gentes de otro tiempo que están así como kaxlanes, mestizos5.

\footnotetext{
${ }^{4}$ Pitarch (1996: 85-88), en Ch'ulel: una etnografía de las almas tzeltales, retrata magistralmente el valor y carácter de las palabras para este grupo étnico. Éstas, señala, aunque invisibles, no difieren mucho del resto de cosas tangibles, poseen cualidades sensibles y propiedades de animación: forma, temperatura, sensibilidad, motricidad y voz. Asimismo, a pesar de que no puedan desembarazarse de su impronta inicial, poseen una conciencia independiente de quien las pronuncia, hablando por sí mismas. De ahí que la discreción sea una de las virtudes más apreciadas y el ideal de persona por excelencia remita a alguien comedido en el uso del lenguaje.

${ }^{5}$ Quisiera advertir, antes de continuar la reflexión, que si bien empleo el concepto de ahora, este ahora es un tiempo que ha ido produciéndose paulatinamente aproximadamente desde
} 


\section{EXPRESAR LA HUMANIDAD. EL VALOR DE LAS PALABRAS EN LA CONSTRUCCIÓN DE NUEVAS SUBJETIVIDADES INDÍGENAS EN LA "MODERNIDAD"}

Para tzotziles y tzeltales las palabras no son exclusivamente señal de humanidad, sino que pueden serlo de "verdadera" humanidad. Así, en primera instancia y a nivel general - tal y como dicta el binomio lengua/identidad—, son gente "verdadera" en tanto hablantes de su lengua, denominada batsil k'op ("palabra verdadera" en tzeltal) y bats'i k'op ("palabra verdadera" en tzotzil) respectivamente. De manera que en gran medida son (y son lo que son) en función del uso que hacen de ella. No cabe duda, entonces, de que ésta siempre es "verdadera" en sí mientras que la persona tzotzil o tzeltal sólo lo será de acuerdo a cómo la articule (teniendo en cuenta los parámetros expresivos culturalmente normados); o lo que es lo mismo, siempre y cuando se muestre competente en su uso. Tal competencia deviene, en gran medida, de la capacidad que tanto cabeza (razón) como labios tienen para darles su forma correcta, siendo la "palabra verdadera" un ideal —al igual que el hombre o mujer "verdadero/a» - al cual se debe tender a lo largo de la vida durante las etapas de maduración personal.

Y es que, como bien explica Pitarch (2006: 124-125) de los tzeltales — caso que tomo para ilustrar esta cuestión-, se cree que las palabras brotan del interior del corazón y antes de ser dichas con el habla hacen un recorrido corporal pasando, en primer término, por la cabeza para ser elaboradas después en la boca y moduladas posteriormente en los labios, elemento que les proporciona su forma (tzeltal) conveniente. De esta manera el primitivo saber del corazón es transformado por la "voluntad de la cabeza". Tal modo apropiado de construcción del habla (que considero idéntico al tzotzil) tiene que ver con su expresión como "palabras verdaderas" y remite a una tipología de persona cabal, comedida y mansa de la que se dice no juega con ellas; esto es, alguien próximo a ese ideal social por excelencia de mujeres y hombres "verdaderos" ${ }^{6}$. Pero, sobre todo, para que las palabras tengan esa cualidad (car-

mediados del pasado siglo. En este sentido, por ejemplo, en la década de los sesenta, Esther Hermitte (1968) —a propósito de los efectos de las políticas del Instituto Nacional Indigenista (INI) - empleó la categoría de "indios revestidos" para denominar a aquella avanzadilla de indígenas ladinizados.

${ }^{6}$ El manxu, de "Corazón grande" (muk'ta yo'nton o muk'ul o'nton), es el ideal de persona por excelencia: obediente, humilde, reflexiva y tranquila. Es capaz de aguantar ( $-k u c h)$ la rabia que se acumula tras los conflictos, no reacciona a las provocaciones y su corazón colabora con la cabeza para modular y controlar la expresión de los deseos y sentimientos en pos del silencio y la armonía (Groark, 2005: 159-164). Para una definición, los sinónimos y su sentido, ver Laughlin (2007: 187, 220, 367, 402-403) donde, además, anota que amansar también se dice nopvan (crecer bien bajo el cuidado de uno), y sería sinónimo de vaxal (apacible, de buen humor, calmado, grande, quieto) y vaxet (apacible, de buen corazón, obediente, paciente, quieto, tratable). Entre los tzotziles, como bien observara Villa Rojas (1985: 190), el carácter humilde y tolerante es el preferido en oposición a quienes tienen "sangre fuerte", peligrosos para una correcta sociabilidad. También en Amatenango, según Nash (1970), se les concede un valor especial a los "suaves" cuyo comportamiento es de igual consideración, cualidad conocida como kunkuntik. Un informante de Groark (2005: 140-142) le explicaba que si el corazón es grande la persona tiene todo bajo control ( $x u^{\prime}$ yu'un skatol), los problemas se quedan allí mismo, no crecen y se convierten en frío (mu'yuk tey mas ta sk'ak'ub, ta sikub). Su corazón está en silencio (tz'ijil), no empeora la situación, es tranquilo y puede soportar cualquier cosa. 
gada de identidad) deben estar desprovistas de cualquier emoción y aderezo gestual $\mathrm{y}$, por ende, quien las emite ha de ser una persona real y metafóricamente cerrada. Así es (y debe ser) en principio el lenguaje de los adultos (y los adultos mismos), más educado y discreto respecto a la expresión de las emociones mientras que - como observa Pitarch - a la juventud todavía se le permite recurrir al ixta k'op, habla informal o de broma, y a la infancia pronunciar palabras sueltas en castellano, a menudo insultos.

De este modo la construcción de la persona (y de su identidad étnica) es un proceso paulatino que corre paralelo a la adquisición del lenguaje y a la contemplación de las normas culturales del habla que lo rigen. Por lo que la educación familiar y la socialización en la costumbre van encaminándola, a través de la instrucción en el uso de la "palabra verdadera", hacia el fin de convertirse en hombres o mujeres de igual cualidad. Es decir, tal y como advierte Paoli (2003), el proceso de maduración personal está orientado a producir un tipo de personas que se dice "hablan verdad"; lo cual supone no sólo hacerlo en tzeltal — caso igualmente analizado por él—o tzotzil, sino hacerlo con razón y de manera ajustada a lo que es el habla correcta. Es más, una característica que se les atribuye a los batsil ants y batsil winik tzeltales es que no juegan ni hieren con las palabras ( $m a^{\prime}$ xa ixta k'op), cumpliendo siempre con lo que se dice y obedeciendo la palabra de Dios. Siendo así se presuponen otras cualidades personales que remiten a la corrección corporal (del gestus y el atuendo) y a la etiqueta social que identifican al arquetipo de persona social por excelencia; a ese modelo de ser moral e idealmente perfecto para la vida en sociedad: cabal, humilde (p'ekel —en tzeltal—, manxo —en tzotzil-), comedido en el empleo del verbo y en la gestión de su presencia, considerado con los demás y socialmente cumplidor, respetuoso y responsable ${ }^{7}$. Una persona, por consiguiente, cuyo carácter está alejado de la altivez y la arrogancia ( $m a$ ' stoy sba, "ser alzado o arrogante" en tzeltal y jtoy-ba en tzotzil), como precisamente se expresa que son los del "nuevo crecimiento", denominados ach' chi'eletik, o los del "nuevo vivir", también llamados ach' kuxlejaletik, en la 'modernidad' tzotzil'.

\footnotetext{
${ }^{7}$ Precisamente observa Pitarch (2001) que el etnónimo que se aplican a sí mismos los tzeltales, batz'il winik (hombres verdaderos", "hombres genuinos"), debe interpretarse en este sentido. No como seres que son por nacimiento o por definición humanos genuinos, sino que han llegado a ser auténticos humanos en el sentido de que su cuerpo ha aprendido a comportarse de manera social y moralmente correcta.

${ }^{8}$ López García (2003: 323-325, 335-336) señala, también, cómo entre los ch'orti' del oriente de Guatemala cuando alguien es calificado de "buena sangre" quiere decir que manifiesta prudencia, humildad y tolerancia, teniendo la cualidad de "hablar con modo"; esto es, de manera sensata y comedida, mansa, con respeto y no mintiendo ni burlándose. Esta tipología de persona, cuerpo/moralidad, tiene una temperatura "cordial" y remite al modelo ideal de comunidad congruente (López García 2006: 398) "[...] donde las interacciones entre la gente se guían por el principio del respeto y la corrección: las palabras son amables, intentan llegar al corazón del otro [...] La apertura controlada de la boca y del oído tiene su expresión social en que se impide el chisme y se evita el "reparar" (escuchar) en los demás. Se trata también de una comunidad donde se controlan las alianzas sociales, donde se establece quienes son convenientes e inconvenientes para la interacción social y, por tanto, para la relación sexual. Eso implica comedimiento en las relaciones sexuales. El hecho de que pene y vagina estén comedidamente abiertos posibilita alianzas sociales cordiales" (López García 2006:402-403).
} 
En definitiva, de entre todos los aspectos que tzeltales y tzotziles contemplan para valorar la humanidad y la ética de alguien, el habla es el mayor indicador moral e identitario de la persona. Pero no sólo deben enunciarse las palabras apropiadas en las circunstancias oportunas sino que, además, deben cuidarse aspectos como el tono, el timbre y la cadencia (Pitarch 1996: 85-88; Pitarch 2000a: 2). Así, alguien es bueno si su palabra es de igual carácter; si, como señala Paoli (2003: 30-33, 109-111) para el caso tzeltal, «[...] cree en la palabra y obedece la palabra de la comunidad. No miente. Lo que dice es aquello que hace y su corazón es bueno. [...] No juega con las palabras. Es justo su decir y ciertamente es fiel al cumplir lo que ha dicho". Exactamente como se piensa que no es la juventud, los del "nuevo crecimiento" o los del "nuevo vivir". Éstos "ya se manifiestan de diferente manera" que la gente adulta y anciana y son, por lo general, y debido a su actitud rebelde, tildados de toj jtoy ba ("demasiado alzados" o altivos) ${ }^{9}$, lokos o simarrones (cimarrones). De ellos se dice que son como perros, de ahí la denominación toj $t z^{\prime} i$ ' ("demasiado perro"), que equivale a afirmar que se sobrepasan y "hacen lo que su corazón dice" o "lo que su corazón habla" sin contemplación alguna de las repercusiones sociales de sus actos ni arrepentimiento una vez los han realizado; es decir, que actúan "con todo su corazón". No obedecen, se extralimitan y no tienen respeto ${ }^{10}$. Todo ello es sintomático de poseer un carácter fuerte que es notado como toj tzozt yo'on ("demasiado fuerte su corazón") o toj tzozt chichel ("demasiado fuerte su sangre"). Podría decirse que en ellos tanto el saber del corazón cuanto sus apetitos surgen de sí sin haber sido elaborados como debieran, y es en las personas cabales o de razón, por la cabeza y la boca/labios. De manera que las palabras, y los gestos y actitudes que las acompañan, emergen a lo público cargadas de emociones e impregnadas con ellas, lo cual ha supuesto un cambio considerable en la construcción de nuevas subjetividades indígenas en la 'modernidad' de la región.

\footnotetext{
9 Tipología de persona que describió Laughlin (1975: 345-346) con adjetivos que aluden la arrogancia, la desobediencia, la mezquindad, la prepotencia, el orgullo y la soberbia, la altanería y la agresividad. Toj es un adjetivo que significa "muy", "tan". Laughlin da los siguientes significados a toy ba: ser agresivo, altivo, desobediente, faccioso, regañón, tacaño. Ésta es una expresión que se forma con la raíz toy (volverse poderoso, volverse rico) y que acoge otras expresiones: toy e (hablar enérgicamente, hablar con fuerza); toyel a'i (ser desobediente, obstinarse en hacer mal). Invita él al referir la raíz toy a ver el significado de la raíz muk' (grande, exagerado), y de muk'ultas, que, entre otras acepciones, alude a ostentarse (2007: 312, 316-317). De este modo, el $j$ toy- $b a$, rebelde, exagerado y excesivo en todas sus expresiones, propenso a actos impulsivos y a dejarse llevar por las emociones, constituye una amenaza permanente para las relaciones sociales.

${ }^{10}$ Con trazo grueso podría decir que las maneras que revelan respeto — principio tradicional que regula el modo de establecerse las relaciones sociales y garantiza el correcto funcionamiento de la sociedad (tradicional)—, que significan el modo de proceder suave y con obediencia de quien contempla los consejos, de las personas "cabales" o de "razón" con un carácter personal sociable y humilde propiciador de la buena convivencia, devienen del control sobre el cuerpo y las emociones ejercido gracias a la "voluntad de la cabeza", que se forma a través del aprendizaje y la experiencia cultural. Por otra parte, "perder el respeto" equivale a actuar a la fuerza y parece significar el abandono de la persona a la "voluntad del corazón" basada en las emociones que impele hacia hábitos de kaxlanes (castellanos, mestizos) y hacia una estética más moderna asociada con la identidad mestiza.
} 
Precisamente en otro lugar (Neila Boyer 2012) advertía cómo en este tiempo ach' kuxlejal otros principios basados en las emociones - más próximos al mundo mestizo y a la apertura emocional que lo caracterizan, frente a la contención típica de la tradición indígena ${ }^{11}$ — han irrumpido con fuerza como elementos deseados y deseables para entablar lazos interpersonales y orientar la experiencia; hecho interpretado como un dejarse llevar descomedidamente por los sentimientos. Esta novedosa manera de ser apunta a la adquisición de hábitos mestizos en el comportamiento cotidiano, guardando relación dicho carácter exagerado y descomedido con la manera de concebirse la 'modernidad'. Se establece así un contraste entre el "antes" o mas vo'ne y ésta, o el "nuevo vivir" (ach' kuxlejal) —efecto de un estilo distinto de crecer-, que implica justamente una oposición de caracteres expresada en términos de fortaleza (aspereza) o debilidad (suavidad) respectivamente, y de temperatura: sobrepasado de calor o tibio como cualidades simbólico/metafóricas que condensan una gran cantidad de atributos ${ }^{12}$. Categorías que según su preeminencia describen el cambio y sugieren diferencias fundamentales en la manera en que se producen las cosas y se está en el mundo: tradicionalmente con equilibrio y armonía, en la 'modernidad' con exageración y violencia. De este modo, si la tradición privilegia y valora la suavidad — que refiere el equilibrio en todos los aspectos de la vida, a la par que es señal de la correcta sociabilidad, de la "buena vida", lekil kuxlejal-, así como la templanza (tibieza), que significa sumisión, obediencia, humildad, contención emocional, mesura y armonía gestual, rasgos distintivos de quienes crecieron y viven conforme a la costumbre y que definen a alguien manxo, el carácter asociado a la 'modernidad', el del jtoy-ba, se caracteriza por la fortaleza y el exceso de calor en la sangre que hace de los ach' ch'ieletik personas más conflictivas cuyos comportamientos asociales dan lugar a una sociedad desigual, intratable y abrupta. Sus palabras, embebidas de emociones, ponen de manifiesto no sólo que otro tiempo es presente sino que en este "nuevo vivir" se está produciendo una reconstrucción de las subjetividades indígenas que les impele a pensar en una humanidad, por así decirlo, más ladinizada.

En este sentido, debido precisamente a que con la irrupción de la 'modernidad'

${ }^{11}$ Sobre el tradicional hermetismo indígena tzeltal y tzotzil véanse Haviland (1982, 1988), Haviland y Haviland (1983), Pitarch (1996), Groark (2008).

${ }^{12}$ Esta dicotomía, a pesar de emplearse contemporáneamente para definir el cambio generacional, ya era utilizada desde antiguo para efectuar calificaciones personales individuales. A este respecto, por ejemplo, en la reconstrucción del entorno cultural de los tzeltales a finales del siglo XVI, Mario Ruz (1985: 107-108) anota en el epígrafe referido al cuerpo humano los siguientes términos registrados en su día por el dominico Fray Domingo de Ara. Dice así: "Cahc, término que denota al fuego y de allí a la palabra áspera (cahcal cop) y a la bravura, la fortaleza y la valentía, se vierte en enojarse, cahcub otan ("tener caliente, bravo, el corazón"), y si el hombre apasionado es un cabc vinic, cacub otan ta yliba significa apasionarse de enojo ("tener caliente de enojo el corazón"). Vinculado con ellos está chetchonel otan, ("encenderse de enojo el corazón") que Ara vierte en castellano como "encendimiento". Lamtzaagh, cosa pacífica, participa en la formación de amansarse, lamtzaagh otan: "pacífico su corazón", y si cic significa frío, cosa mansa, $y$ ciqbil mansedumbre, nada más correcto que denominar cicublezegh otanil ("el que enfría o amansa los corazones") al pacificador, el cual también era denominado ghcunightez bey otan, ("el que entibia o refresca el camino del corazón") u olantezegh, de olantez yotan: "descansar su corazón"m. 
se insta a la juventud a una mayor apertura comunicativa y expresividad emocional ${ }^{13}$, se están configurando nuevas subjetividades indígenas alejadas de ese ideal de cabalidad y comedimiento. Tanto así que, como he expresado, si bien antaño la tipología personal por excelencia era el manxo ahora, en el "nuevo vivir" ( $a c h$ ' kuxlejal), lo son el jtoy-ba, el loko/a y el simarrón (cimarrón). Y es que si en el pasado resultaba socialmente contraproducente mostrar las emociones y dejarse llevar por ellas, actualmente la 'modernidad' (en la figura de múltiples actores: desde el magisterio hasta el personal del asociacionismo civil) está instruyendo en las bonanzas del abandono del hermetismo personal y hacia cierta expansión emocional con el objeto de construir un "nuevo vivir" más acorde a las necesidades de un mundo globalizado $^{14}$. Al respecto, mi joven amiga tzotzil Cecilia decía en cierta ocasión en el contexto de un acto internacional de una ONG:

[...] En los viejos tiempos los hombres y las mujeres no sabían lo que era una emoción o un sentimiento pero las organizaciones nos han descubierto que existen. Nadie nos enseñó a expresarlos. [...] Nosotras hemos aprendido a expresar nuestros sentimientos a través de la educación y los talleres. En la escuela el maestro habla con nosotras sobre nuestros sentimientos y las mujeres mayores aprenden en los talleres al respecto porque no asistieron a la escuela. De esta manera las mujeres se han dado cuenta de que pueden hacer más de lo que piensan. Esto ha ayudado a las mujeres a hablar sin miedo y a aprender el significado de algunas palabras como el respeto, la confianza, la dignidad, la emoción y el agradecimiento, porque estas son las palabras que usamos en los talleres. No hace mucho, para todas nosotras, estas palabras no se conocían. De esta manera podemos organizarnos mejor y esto nos ha ayudado a tener nuevos proyectos.

En la misma línea mi amiga Margarita, también joven tzotzil, me comentaba:

[...] en las comunidades no saben que hay que expresar los sentimientos, por lo mismo que te encierran pues. Yo, por ejemplo, no lo puedo callar, yo lo demuestro — advertía sabiéndose considerada una persona alzada-. Porque hay personas que son muy fuertes [de carácter] y cualquier problema no lo aguantan dentro y lo dicen en la cara; pero hay personas que tienen la fuerza muy débil y no pueden resistir los problemas y no pueden salir de ellos. No los cuentan y a nadie dicen sus sentimientos. Es muy débil, $a b o l s b a$; es como si seríamos pobre. Ya no saben pensar.

Esto conduce, efectivamente, a pensar en "los del nuevo crecimiento" o ach' chieletik como una humanidad diferente a esa de hombres y mujeres verdaderos/as que lo son en función del uso comedido de la "palabra verdadera". En base a todo lo dicho re-

\footnotetext{
${ }^{13} \mathrm{Al}$ respecto, véase Neila Boyer (2015a).

${ }^{14}$ Anteriormente (Neila Boyer 2012) he puesto de manifiesto cómo en este tiempo que denominan "nuevo vivir", ach' kuxlejal, se ha producido un cambio en el modo de concebir la vida, la cual comienza a entenderse no sólo como algo dado sino como algo que hay que buscar y construir. Este giro se explica a partir de la oposición entre una vida acorde a la costumbre, construida con el favor de Dios, basada en la obediencia, el respeto y la humildad, sustentada por los consejos (mantal) — la "razón" que garantiza la "buena vida" (lekil kuxlejal)—, y cuyo correcto seguimiento hace innecesario "pensar" demasiado los modos precisos para ganársela, y aquella donde la voluntad personal se justifica por el deseo de una existencia diferente cuya procura requiere una reflexión constante para adoptar las decisiones personales más adecuadas a los fines que se pretenden alcanzar. Ésta requiere de otros argumentos que adoptan la forma de retóricas sobre expectativas y "visiones" de futuro.
} 
sulta lógica la apreciación nativa acerca de un nuevo tiempo que les pertenece a "los que apenas está llegando"; máxime ahora que el castellano va adquiriendo mayor protagonismo debido a las interacciones cada vez más frecuentes y cotidianas con el mundo mestizo, por efecto de las migraciones, de los medios de comunicación y de la escolarización, y cuando el habla en tzotzil o tzeltal viene, en cierto modo, perdiendo rigidez en favor de esa apertura que permite mayor expresividad emocional. Ahora bien, como defiendo, la consideración de otra humanidad (y una humanidad más ladinizada) no deviene tanto (y tan sólo) del hecho de hablar en castilla cuanto de hablar (bien sea en castellano o en tzotzil/tzeltal) sin modo. Esto es, con un lenguaje poblado de "malas palabras" (chopol k'op) o "palabras ardientes" y "palabras febriles" (k'ak'al k'op) que incitan a la agresión verbal y promueven el ruido social (Neila Boyer 2015b); o con un habla enérgica, carente de humildad, prudencia y respeto, descontrolada y descomedida, propia de las personas burlonas y chismosas; e incluso con palabras que denotan mayor agencia personal, la desobediencia de la costumbre y la ausencia de la apropiada modestia y gratitud ${ }^{15}$. Es más, con palabras, también — como trataré más adelante-, emanadas directamente del corazón que poseen toda la carga emotiva que se les presupone y construyen discursos novedosos como el amoroso...

Recapitulando, hasta aquí he tratado de mostrar cómo las palabras — sin menosprecio de otros factores culturales, económicos, de relaciones de poder, etc.- - condicionan la humanidad de alguien y, en base a ello y como efecto de la 'modernidad', he sugerido que tras la observación nativa acerca de un "nuevo vivir" y de las denominaciones con que se nombra a las generaciones más jóvenes (ach' chieletik o ach' kuxlejaletik) subyace precisamente la idea de una humanidad distinta en este tiempo ach' kuxlejal de aquella socializada en la costumbre. Esta consideración se sustenta en la observación de un cuasi generalizado uso incompetente del lenguaje entre la juventud; esto es, de un hablar sin respeto ni gratitud, de manera imperativa, sin modo... Ahora bien, la competencia o incompetencia en el habla, que determina el ser indígena u otra cosa distinta, viene condicionada por el tipo de palabras y discursos que construyen a la persona; cuestión que trataré a continuación. De manera que las palabras adquiridas durante el proceso de maduración personal, y que forman parte substancial del ser, supeditan asimismo el tipo y modo de palabras que se profieren y les califican e identifican. En este sentido, alguien socializado en la costumbre y conformado por un considerable volumen de "palabras antiguas" hablará de

\footnotetext{
15 Anota Stross (1973: 278, 263) cómo en Tenejapa hablar mal integra a quienes lo hacen a espaldas de la gente y difunden conversaciones que oyeron. Mientras que hacerlo bien es ser elocuente y aportar buenas ideas de manera calmada y deliberada. Por ello los castigos más fuertes en la infancia tienen que ver con la mentira y el insulto. Es de tal importancia la competencia lingüística que antes de nacer un bebé le pedirán a los dioses que no salga tartamudo, ladrón ni borracho; modelos de persona que, según observa López García (2003: 336) —quien reportaba lo mismo entre los mayas ch'orti‘ del oriente de Guatemala-, representan los valores del cuerpo violador y del violado por la palabra. Él advierte que en los rituales para favorecer que el bebé "venga bien al mundo" se ruega que nazca "bien bonito y platicón" para que no sea "vergüenzudo ni corajudo"; también que no sea tímido ni tartamudo. En definitiva, que venga con "buena sangre" como expresión clara de que hablará respetuosamente, será discreto y tranquilo en sus juicios (López García 2003: 323).
} 
forma cabal, como un hombre o mujer verdarero/a, como un indígena. Por otro lado, el habla de la persona socializada mediante otras retóricas y discursos globalizados, e instruida en una apertura comunicativa y mayor expresividad emocional, reflejará - en base a ello y en consideración de los mayores - cierta ladinización. De este modo es posible argumentar que ahora que la juventud se socializa en un medio atiborrado de discursos más o menos novedosos emergidos por efecto de la 'modernidad' se está produciendo un proceso de construcción de nuevas subjetividades indígenas a la par que un cuestionamiento de sus identidades étnicas. Quiero en el siguiente epígrafe abundar en esta cuestión y tratar de demostrar, desde un punto de vista emic, cómo efectivamente el tipo de palabras recibidas durante el proceso de maduración personal produce unas tipologías personales u otras para, a continuación, ejemplificar cómo el novedoso discurso amoroso - de entre todos los discursos asociados a la 'modernidad': el de los derechos humanos, los del cristianismo moderno, los feministas y de derechos de la mujer, los desarrollistas, los del neo-indigenismo, etcétera- está sirviendo para la construcción de nuevas subjetividades e identidades indígenas al margen de la idea de mestizaje de las sociedades indígenas contemporáneas.

\section{LAS PALABRAS MANTAL COMO SUBSTANCIA DEL SER INDÍGENA}

Siguiendo desde una perspectiva tzeltal que considero muy similar o próxima a la tzotzil, pero que gracias al trabajo de Pitarch (2000a: 3; 2000b: 130-131; 2001: 132; 2003: 66; 2006: 353-354) ilustra mejor estas cuestiones, alguien éticamente formado o con un desarrollo moral completo —es decir, cabal— es quien ha adquirido el suficiente juicio y sentido común gracias a las palabras de los consejos (mantalil) como para considerarse que posee un cuerpo correcto $^{16}$; el cual sólo se logra a edad avanzada dada su fabricación continua desde el nacimiento. Se entiende que éste es producto de la vida social y sólo aproximadamente en torno a los cuarenta o cincuenta años es posible suponer que se ha alcanzado un grado de madurez suficiente; lo que equivale a decir un lugar social y una calidad ética aceptables, implicando, no olvidemos, el uso de la palabra de forma competente. Tanto es así que, por ejemplo, el término tzeltal que designa a una persona mayor, k'otem (del verbo k'ot, "llegar"), significa "terminado", "completo"; esto es, con un cuerpo formado al fin en el sentido de que se comporta de un modo socialmente idóneo: habla bien, viste adecuadamente, gesticula correctamente y se alimenta apropiadamente (todo ello en consonancia con la idea de que el habla competente va ligado a otros aspectos socializadores de la persona, como se dijo al inicio). En esta producción corporal intervienen, sobre todo, las palabras; concretamente aquellas que transmiten las normas y valores culturales

\footnotetext{
${ }^{16}$ Pitarch, en un magnífico trabajo sobre el laberinto de la traducción de la Declaración Universal de los Derechos Humanos a lengua tzeltal, analiza este concepto. Él lo define como "[...] lo que se dice a alguien sobre lo que conviene o no conviene hacer" (2001: 131-133). Esto es, el conjunto de preceptos ofrecidos a la infancia y juventud con el fin de que observen un comportamiento socialmente apropiado; de que actúen con razón, piensen, sigan el camino, adopten la costumbre, adquieran su forma de vivir y su forma de hacer las cosas dentro de los márgenes culturales y el orden establecido.
} 
de la costumbre y que son dichas bajo la forma de mantalil (consejos). Pudiéndose afirmar — como bien él hace- que el cuerpo, al momento de nacer, es tabula rasa y debe ir construyéndose tanto física como cultural y moralmente durante la vida. De manera que tanto para tzeltales como para tzotziles - añado yo- el desarrollo personal es a la vez físico y moral; siendo un aspecto condición necesaria para el otro. Un proceso en el que las palabras de los consejos intervienen de forma decisiva, pero no inmaterialmente — tal y como se supone en Occidente-, sino físicamente, como substancia que es albergada en el cuerpo.

Quisiera subrayar esta cuestión, pues pareciera como si estas palabras formadas con la materia de la costumbre fueran teniendo cabida en el cuerpo de la persona y una capacidad similar a la sangre para determinar la vida y la experiencia cultural. En este sentido, así como la sangre está relacionada con las entidades anímicas, lo innato, con el carácter de la persona (talel) y sus emociones e inclinaciones, en definitiva, con un tipo de saber del corazón que ha de ser modificado y transformado por la cabeza; las palabras de los consejos, como substancia que también son, se asocian a la costumbre, lo adquirido, y son, precisamente, las que ayudan a llevar a cabo dicha transformación. Es más, como observa Pitarch (2001), tal formación ética y moral obtenida progresivamente mediante la socialización familiar desde la primera infancia gracias a los consejos radica en la cabeza y supone una de las dos conciencias o pensamientos que se poseen. A diferencia de ella, que existe sólo potencialmente al momento del nacimiento y se va creando a lo largo del desarrollo individual, la otra, la del corazón, está completamente hecha desde el principio y en este proceso es doblegada por las palabras mantalil que "atraen el corazón". Y es que se dice que éstas son hermosas en sí mismas y mueven los sentimientos. Además, es importante mencionarlo, están asociadas a la armonía social o a lo que desde una perspectiva New Age se ha considerado "buen vivir", lekil kuxlejal. Tanto así, que a propósito de las reflexiones de un informante apunta Pitarch (2001: 133, 136, 148) cómo están dirigidas a reconocer, junto con la bondad, la belleza del mundo, de manera que no se producen exclusivamente en la relación entre los hombres, sino que también incluyen la relación entre las personas y el mundo.

En este sentido, si la sangre da la vida las "palabras antiguas" expresan cómo se ha de vivir. De modo que cuando un cuerpo no está adecuadamente lleno de consejos, esto es, apropiadamente construido física y moralmente, lo que da lugar a una tipología personal concreta: la persona mansa o cabal, resulta más fácil que albergue - y hablo literalmente- otro tipo de palabras que igualmente lo construyen, definiendo su juicio, su corporalidad, su calidad moral, su lugar social... En definitiva, su subjetividad e identidad. Tal es el caso de tipologías personales que parecen abundar en la 'modernidad' indígena de la zona: rebeldes, lokos/lokas, cimarrones, alzados/as... De ahí que, como consideran los tzeltales, alguien pueda acumular mucho o poco mantal $\mathrm{y}$, por consiguiente, ser más o menos cabal en función de la cabida que a lo largo de su existencia dé a esas palabras emitidas con el fin de que observe un comportamiento socialmente apropiado ${ }^{17}$. Y es que ellas, como pone de manifiesto Pitarch (2001:

\footnotetext{
${ }^{17}$ Esta formación ética se distingue del desarrollo de la inteligencia (p'ijubtesel). Si bien ambas se adquieren progresivamente y radican en la cabeza, la inteligencia guarda relación con el conocimiento de carácter más técnico y la capacidad de aprender. Además, a diferencia de la
} 
132-133), prestan atención prioritaria a las cuestiones de corrección corporal y etiqueta social; en especial a aquellas que tienen que ver con la demostración de respeto. De forma que, como bien afirma, mantalil constituye una ética de vida que se elabora en, y guarda relación con, el cuerpo donde éste constituye el escenario necesario para el desarrollo moral; el instrumento expresivo fundamental de su calidad ética y el locus de la diferencia. Quisiera subrayar esta cuestión pues si bien el género mantalil compone una ética, también representa una estética que distingue, mediante los hábitos sociales (lo que se come; lo que se habla y cómo se habla; la forma de moverse, vestirse y llevar la ropa, etc.) a unos de otros. En definitiva, determinada compostura personal, etiqueta social y lenguaje comedidos emocional y verbalmente hablando son reflejo del respeto y de una ética de vida que garantiza el apropiado desenvolvimiento del sujeto en la sociedad; que revela el actuar con razón, de manera cabal, la adopción de la costumbre, la asunción de los márgenes culturales y el orden establecido; que pone en evidencia una concepción de la vida y un modo de proceder en ella (de estar-en-el-mundo) en consonancia con la tradición (Pitarch 2006: 354).

Al hilo de la idea de que las palabras mantal parecen ir teniendo cabida en el cuerpo de la persona y una capacidad similar a la sangre para vitalizarlo, en un sentido cultural, quisiera hacer una breve digresión con objeto de apuntalar esta impresión - de sangre y palabras como sustentos del ser- y avanzar un poco en la reflexión sobre estas cuestiones. En "Los dos cuerpos", describe Pitarch (2013: 37-63) lo que parece ser la existencia de dos clases de cuerpo — valga la redundancia- en la persona tzeltal (y en su concepción ontológica): el "cuerpo-carne" (bak'etal —de bak'et, "carne"-) ${ }^{18}$, que es unión de carne y fluidos, sensible pero sin capacidad de relación social con los demás seres; y el "cuerpo-presencia" (winkilel —de la raíz -win, "aparecer", "mostrarse", que conforma la palabra winik traducida comúnmente por ser humano, cuerpo o persona-) ${ }^{19}$; un sujeto activo de percepción, sentimiento y cognición comprometido en una relación intersubjetiva con cuerpos de la misma especie ${ }^{20}$. Para el propósito que persigo, y siguiendo su argumentación, paso a describir ambos.

moral, cuyo desarrollo comienza en la primera infancia, la inteligencia inicia su desarrollo más tarde (Pitarch 2001: 132).

${ }^{18}$ El vocabulario de lengua tzeltal del siglo XVI del fraile Domingo de Ara (1986) traduce bak'etal como "cuerpo, carnal cosa" (Pitarch 2013: 39).

${ }^{19} \mathrm{El}$ diccionario de lengua tzotzil de Robert Laughlin (1975) traduce el morfema win por "aparecer, ser expuesto, ser visto, ser escuchado, ser distinguido, darse a conocer». Por otro lado, y como bien anota Pitarch (2013: 42-43), en el diccionario etimológico de las lenguas mayas compilado por Terence Kaufman (2003), winik (y sus cognadas) abarca los significados de persona, cuerpo, ser humano, gente, natural (indígena), llegar a ser hombre, dueño, corpulencia. Pitarch sospecha que el término win fue tomado de las lenguas mixe-zoques, donde está asociado con cosas como el poder (capacidad de hacer algo), el rostro, la superficie, el cuerpo, uno mismo (forma reflexiva del pronombre personal), la envoltura y, también, la máscara. Es decir, algo destinado a ser mostrado, pero que también sirve para ver. Asimismo, se encuentra también esta raíz en winal, cada una de las unidades de veinte días del calendario solar maya, y en el número veinte, hasta el punto de que Dennis Tedlock (1993) define el término quiché winak ("ser humano") como "ser vigesimal" en alusión a los veinte dígitos.

${ }^{20}$ Observa Pitarch (2013: 43) que un examen de los diccionarios de lenguas mayas contemporáneos y coloniales demuestra que la distinción léxica entre ambos cuerpos es común a esta familia lingüística. 
El "cuerpo-carne" comprende el conjunto del cuerpo humano, salvo aquellas partes por donde no circula la sangre (huesos, vello corporal y uñas). Ésta es el elemento básico que lo vitaliza. Un dato revelador para comprender la importancia de la sangre en su existencia es que el feto, mientras se gesta, carece de él formando todavía parte del "cuerpo-carne" de la madre y teniendo, en cambio, "cuerpo-presencia". Y es que en tanto permanece en el vientre vive gracias a la sangre materna: respira y se alimenta de ella; y sólo a partir del parto el recién nacido adquiere un "cuerpo-carne" propio ${ }^{21}$. El "cuerpo-presencia", por otro lado, abarca el conjunto del cuerpo humano, incluidos cabello, uñas y huesos. Es un cuerpo que existe para ser percibido y a través del cual tiene lugar la percepción; esto es, un cuerpo involucrado en relaciones intersubjetivas con sus semejantes. De hecho, mientras que el "cuerpo-carne" se caracteriza por ser una reunión de partes y tener un carácter pasivo, funcionando como un objeto, el "cuerpo-presencia" es un todo integrado y activo experimentado como un sujeto: hace $\operatorname{cosas}^{22}$. En definitiva, es la figura, la forma corporal, el semblante, la manera de hablar, caminar, vestir la ropa. Así, mientras el "cuerpocarne" no posee una forma determinada, el "cuerpo-presencia" tiene, en cambio, aspecto específicamente humano ${ }^{23}$. Lo que quisiera subrayar de aquí es la impresión de que este "cuerpo-presencia", dada la importancia de los consejos para construir un ser moral y corporal apropiado, y tal y como Pitarch lo describe, se substancia en gran medida de palabras. Refiriendo en cierto sentido esta observación anota él cómo ambos cuerpos requieren ser fabricados de una manera continua, pero en tanto el "cuerpo-carne" es resultado directo de la alimentación (la comida se incorpora literalmente como carne y sangre) y de ciertas condiciones ambientales, el "cuerpo-presencia" es fruto del aprendizaje o la adquisición de los hábitos sociales (etiqueta social, gestos, indumentaria, etc.) y del lenguaje.

\footnotetext{
${ }^{21}$ Incluso entonces, afirma Pitarch (2013: 40-41), éste no es totalmente independiente y el bebé necesitará seguir "respirando" a través de la madre. Es por esta razón que el corte del cordón umbilical se retrasa todo lo posible, y por lo que también el bebé deberá seguir siendo amamantado, pues la leche materna no sólo transmite alimento, sino también aire. Incluso durante el largo periodo en que la madre le cargue en la espalda, en una especie de respiración transferida, el estado de su sangre - caliente, fría, etcétera- continuará gestándolo. Y es que entre los tzeltales prevalece la idea de que los sistemas sanguíneo y respiratorio constituyen uno solo. El corazón/estómago recibe el aire inspirado y el alimento y de aquí pasa al resto del organismo a través de la sangre proporcionando la fuerza al cuerpo.

${ }^{22}$ Al respecto, por ejemplo, observa Pitarch (2013: 49) que cuando en los cantos chamánicos de curación son citadas partes corporales concretas, éstas no son tanto fragmentos anatómicos cuanto actividades corporales enunciadas como paralelos semánticos. El par "corazón/labios" expresa la función del lenguaje, de acuerdo con la teoría indígena de que las palabras brotan del corazón y ascienden hasta la boca, donde son articuladas por los labios para producir un habla adecuada; el par "mirada/rostro" remite a la capacidad de los sentidos (vista, oído y gusto/olfato); y el de "manos/pies" o su equivalente, "brazos/piernas" (el total de veinte dígitos que funciona comúnmente como sinécdoque de este cuerpo), refiere la facultad del movimiento articulado y, con ella, la capacidad de trabajar, rasgo definitorio de humanidad.

${ }^{23}$ Cuestión que se revela con claridad si se atiende a los clasificadores numerales con que se refiere a ambos: en lengua tzeltal el clasificador numeral para el "cuerpo-presencia" entre los humanos es $t u l$, que denota una posición bípeda y una figura característicamente humana, mientras que para el "cuerpo-carne" es kojt, que indica una postura cuadrúpeda (Pitarch 2013: 44).
} 
Volviendo a la argumentación, las palabras de alguien —aunque no todas, pero sí las cargadas de razón que compendian los consejos y enseñan cómo vivir en la costumbre, y las de alto contenido emocional que suelen proceder del carácter innatouna vez emitidas pueden llegar a formar parte consustancial de una persona ${ }^{24}$. Tanto así que condicionan y determinan, de algún modo, los hábitos sociales (etiqueta social, gestos, indumentaria), el comportamiento y el estado corporal en términos de bienestar (entendido éste en un sentido amplio). O lo que es lo mismo, reglan el ethos y lo que Pitarch (2013: 42-47) ha denominado "cuerpo-presencia". En base a esta concepción parece lógico que sea posible atisbar las palabras de que está "hecho" uno - o de las cuales carece-, las que confieren sentido a su conducta y subjetividad, efectuando una observación corriente del comportamiento. Alguien que acoge en sí los preceptos de la tradición en la forma de palabras mantal resulta una persona ética, cabal, pulida en la costumbre y con una sociabilidad apropiada. El comedimiento en el gestus, en el empleo de la palabra y en la expresividad emocional son reflejo de que en la persona hay mucho mantalil. Por otro lado, quien carece de este tipo de palabras tiende a demostrar un comportamiento considerado poco sensato y desestabilizador de las relaciones sociales. La exageración gestual, expresiva y emocional denotan su inexistencia y el imperio de la "voluntad del corazón", tal y como parece estar ocurriendo en este tiempo ach' kuxlejal.

Actualmente, en el "nuevo vivir" tzoztil — que paso a ejemplificar a continuación e ilustro con mi propio trabajo de campo-, y debido principalmente a la escolarización, las palabras de los adultos están en crisis. La educación formal ha ido adquiriendo preponderancia en detrimento de la socialización familiar en la costumbre. "Los del nuevo crecimiento" (ach' chieletik) o "los del nuevo vivir" (ach' kuxlejaletik) lo son, en parte, porque van desarrollándose con cierta carestía en su persona de palabras mantal; bien sea porque ya no las reciben debido a la desidia de sus mayores en transmitirlas dado el escaso reconocimiento con que cuentan por parte de la juventud, bien porque desprecian los consejos en tanto entienden que en este "nuevo vivir" las "palabras antiguas" les son de poca utilidad.

${ }^{24}$ Los tzotziles de Chiapas tienen la idea de que los conflictos interpersonales ( $k$ 'op) generan trastornos emocionales en todos los participantes, máxime cuando alguien dice "malas palabras" (chopol k'op) o "palabras febriles" (k'ak'al k'op): actos del habla agresivos, chismes... En definitiva, palabras que "no gustan" y que entran en el cuerpo descendiendo hasta el corazón/estómago; lugar donde en un proceso de cultivo e intensificación interior se reúne el coraje afirmándose que la persona "junta la fiebre de su corazón" (ta stzob yo'onton sk'ak'al), lo que conduce, entre otras y de manera más expresa, a la enfermedad de k'ak'al o'ntonal ("corazón febril"), ti'ol o koraje ("coraje"). Tras una pelea la "fiebre del corazón" permanece en la garganta e impide comer; las "palabras calientes" siguen ahí — palpables y en forma de una masa esférica - si no se bebe pox (aguardiente), o hasta que ingieren algunas tortillas y bajan, yendo a parar al corazón, donde se quedan retenidas y comienza el dolor. De este modo ese cúmulo de palabras, como una masa esférica, representa las que nunca salieron por la boca y pueden crecer allí, endurecerse y extenderse por el cuerpo a través de la sangre. Explicando esta etnofisiología emocional Groark (2005: 159-164) advertía cómo, de hecho, gran parte de la teoría de la emoción tzotzil parece basarse en la hipótesis del contagio a través del cual las emociones negativas expresadas adquieren la forma de una especie de sustancia perjudicial que puede acceder al cuerpo de su objeto. 
Algunos todavía se portan bien cuando lo topamos en el camino y es como nuestros padres estaban acostumbrados - me contaba Pascuala, una mujer tzotzil adulta—, otros, ya cuando pasamos, no hablan, no le importa si te pasa a traer [empujar], ya sea hombre o mujer, no hablan, es como si fueran un perro. Ya hay muchos, es así como se va perdiendo, aunque sepas algo de cómo empezó nuestra forma de vida o de lo que nos decían nuestros padres ya no le pone interés. Él se sobrepasa, él te dice todo, es como si te estuviera dando consejos. Y ahí iqué puedes decir! Ya nada, se ve que no obedece. Él empieza a pensar lo que su corazón manda, cómo va a vivir. Según para él es lo que va a seguir para poder vivir y para ver si así va a pasar, si puede vivir así, es lo que piensa. Pero ya no le pone atención, ya no pregunta: "¿cómo fue que tú viviste?", ni así te dice o nos dice a los que vivimos primero. Ya no lo cree, y de ahí nosotros ya no le queremos decir. Vemos que no le interesa y nos da vergüenza decirles. Cada día está cambiando. Todo lo que ven en la televisión ya todo lo imitan.

Así, si puede afirmarse que las palabras de los consejos determinan el estar-en-elmundo de un modo indígena, existen otro tipo de discursos y retóricas surgidas al amparo de la 'modernidad' y la globalización que les acercan, en principio, al estilo mestizo debido a que instruyen en la apertura (corporal, comunicativa y emocional) propia de ese otro cultural. Nuevas palabras ensambladas bajo la forma de novedosos estilos de habla que son palabras de otro orden y ámbito diferente al de la costumbre y que intervienen en la socialización de las nuevas generaciones, lo que supone una formación ética (o un desarrollo moral) y una expresión corporal (o un desarrollo físico) distintas a las de sus progenitores (que estaban basadas en el hermetismo y comedimiento personal). Esto es, una subjetividad igualmente disímil en ocasiones considerada moral y físicamente incorrecta. De ahí precisamente el borbollón en el tiempo contemporáneo de tipologías personales exageradas (y hasta esperpénticas desde la perspectiva del comedimiento indígena) como el jtoy-ba o alzado/a, el simarron o toj pukuj ("demasiado diablo"), el loko/a o coqueto/a ${ }^{25}$, el toj $t z$ ' $i$ ' o "demasiado perro"... Tipologías, todas ellas, determinadas por un carácter/corazón demasiado fuerte (toj tzozt yo'on) y una sangre de igual cualidad (toj tzozt chichel) que suelen priorizar la "voluntad del corazón" como rectora de la conducta.

Estas personas que han crecido obviando las palabras mantaly, por otro lado, lo han hecho al abrigo de nuevas retóricas que impelen hacia un cambio en las subjetividades indígenas en base a la apertura comunicativa y la mayor expresividad emocional detentan, como no podría ser de otro modo, una corporalidad y un ethos distinto al tradicional. Cuestión que puede ser observada a simple vista, además de en el gestus y en la indumentaria, en el modo de su habla, considerado, ahora ya, incompetente desde la perspectiva cultural de la costumbre. Quizás, sería cuestión de analizarlo —y siguiendo la teoría de Pitarch (2006)—, el gusto por incorporar estas novedosas retóricas sea - como lo era para él la incorporación de nuevos discursos religiosos con motivo de la conversión a otros credos- el gusto por recrear otros cuerpos; unos al estilo de la 'modernidad' que les resultan más apropiados habitar en un mundo globalizado.

${ }^{25}$ Para abundar en esta tipología personal en el contexto de la 'modernidad' y de la construcción de nuevas corporalidades y subjetividades indígenas véase Neila Boyer (2013). 


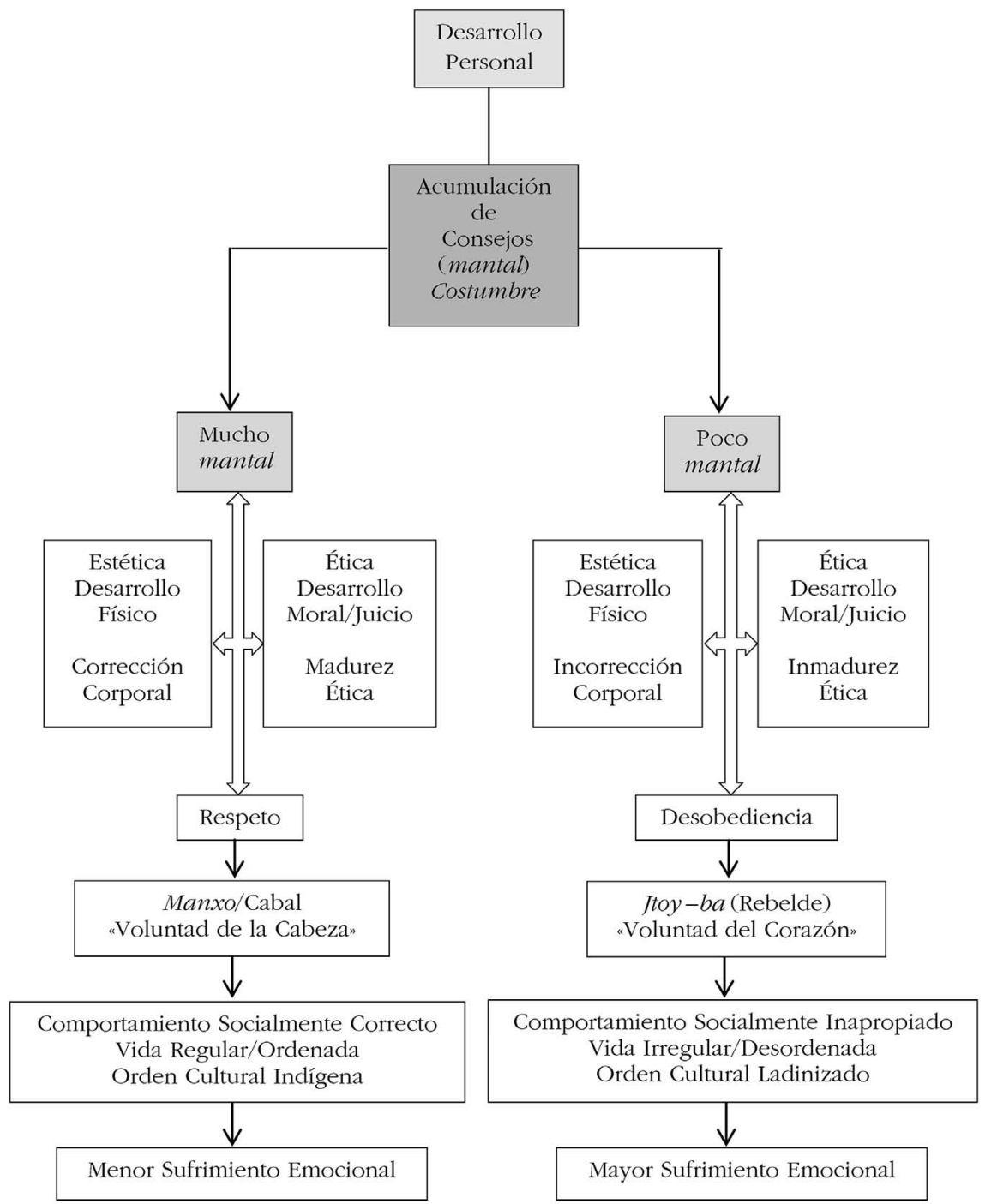

FIG. 1.-El desarrollo personal en función de las palabras mantal.

FUENTE: Elaboración propia.

\section{EL DISCURSO AMOROSO Y LA CONSTRUCCIÓN DE NUEVAS SUBJETIVIDADES IN-} DÍGENAS EN EL "NUEVO VIVIR" TZOTZIL

En 2008 Florisela, una joven amiga tzotzil del municipio de Aldama, me comentó: [...] En la escuela perdemos la pena, cuando llegamos nos hace cambiar. Cuando vamos creciendo cambiamos de diferentes formas cómo somos. Los que no estudian están tran- 
quilos o callados, no hablan, pero los que estudian hablan, platican. Crecemos de diferentes formas. Los que estudian se hablan: "me caso contigo". Se escogen, busca el que le gusta. Los que estudian tienen diferente carácter. ¡Cómo van cambiando! Los que no estudian, por ejemplo los mayores, tienen diferentes actitudes.

Establecía con estas palabras una diferencia generacional (en base a una diferencia educativa) que ha llevado a la apreciación de la infancia y la juventud tzotzil como gentes de un nuevo crecimiento o un nuevo vivir. De ellas se extrae la idea de cómo otros agentes socializadores asociados a la 'modernidad' y la globalización (como lo es la escuela) implican un crecimiento diferente (y un carácter distinto, por cuanto la "Voluntad del corazón" no es doblegada por la de la cabeza) que lleva implícita la noción de cambio. Un cambio que supone un ser otro y el transitar de cierta idea cultural de silencio a otra del ruido ${ }^{26}$, al habla; pero no a cualquier habla, sino a una que es metáfora de apertura (corporal, emocional, comunicativa...) y cuya máxima expresión es la experiencia del 'amor romántico', glosada con el término k'opon baik (hablarse entre sí). De manera que "hablarse entre sí implica tanto un nuevo estilo de habla abierto - concretado en un lenguaje atiborrado de las llamadas "palabras bonitas» - como una corporalidad igualmente más abierta (y propensa al establecimiento de relaciones sexuales). Y esto es así porque desde ciertas instituciones y organizaciones se está precisamente instruyendo en esa apertura personal y comunicativa con otras retóricas que poco tienen que ver con las palabras mantal que embridan los deseos del corazón y garantizan una buena vida.

También María, de San Andrés Larráinzar, me contaba con tristeza que:

[...] tal vez lo que ha empezado, el nuevo vivir, no sirve como estamos viviendo... Ya estamos viviendo mal. Tal vez esto es el nuevo vivir, pero es lo malo. Según [la juventud] es lo bueno pero es lo malo. Cuando alguien hace lo que dice su corazón son los que se sobrepasan, toj $t z^{\prime} i$ ' [demasiado perros], alzados o lokas... Es ahí en donde ha cambiado la vida. Los que saben más, los que han pasado en la escuela, ya no nos toman en cuenta; aunque sepas algo no nos respeta. Los jóvenes han cambiado por lo mismo que ya no tienen respeto y ya no tienen pena [vergüenza, kexlal. iQuién sabe por qué!, tal vez por lo que estudian. ¡Quién sabe cómo piensan!, tal vez por el trabajo. Ahí es donde cambian, en la escuela. Es como decir por la forma de reír; han cambiado sus formas de caminar y sus ropas, y sus formas de peinar. Es ahí en donde cambian. Van aprendiendo el castilla. Ahora se hablan muy bien. Así como ahora un muchacho ya le dice en español: "te quiero", "me gustas".

Se apenaba ella por la falta de respeto y la pérdida de vergüenza que define a los ach' chieletik, "los del nuevo crecimiento"; quienes ahora, en este tiempo ach" kuxlejal, de "nuevo vivir", privilegian el aprendizaje entre iguales obviando las palabras de consejo de sus mayores. Expresaba, además, su desconcierto no sólo por no saber ya cómo piensan sino por el hecho de que piensen por sí mismos; cuestión que de manera privilegiada se pone de manifiesto en el establecimiento de relaciones de pareja hablándose entre sí y no mediante el pedido tradicional de la novia ${ }^{27}$. Advertía, también, que el hecho de hablarse —expresión eufemística, además, del

\footnotetext{
${ }^{26}$ Para un análisis más exhaustivo de este aspecto ver Neila Boyer (2015b).

${ }^{27}$ Para un análisis más en profundidad sobre la idea de pensar por sí mismos y la emergencia del sentimiento amoroso en la 'modernidad' tzotzil véase Neila Boyer (2012).
} 
mantenimiento de relaciones sexuales - con objeto de iniciar el noviazgo suele hacerse en castilla (castellano) y cómo el cambio obrado por la escolarización ha traído consigo una transformación en el gestus y el atuendo; lo que, como se ha visto, implica asimismo un cambio en la construcción moral de la persona.

De manera más general ambas exégesis dan cuenta de cómo la socialización en ciertos contextos asociados a la 'modernidad' ha sido esencial para propiciar en la persona cierta apertura de la que se ha beneficiado la experiencia del 'amor romántico' y la emergencia de un estilo de habla para enamorar poblado de las que denominan "palabras bonitas". Este nuevo estilo supone un hablar sin modo y ha ayudado a la percepción de la juventud como otro tipo de gente, y de humanidad, más próximo al kaxlan que al indígena; una humanidad, por tanto, no verdadera (en el sentido analizado al inicio) por ser descomedidamente abierta y dejarse llevar por los apetitos del corazón. Y es que estas palabras que confieren entidad a ese nuevo tipo de habla, investidas de emociones, distan bastante de las consideradas "palabras verdaderas" siendo, en cambio, adscritas a la categoría de chopol k'op ("malas palabras"). Palabras, también, que significan ruido y distorsión social pero que tratan de ser encauzadas por parte de la juventud en los márgenes de la costumbre (Neila Boyer 2015c). Por otro lado, hablar así es un hecho indicativo de que la persona no está siguiendo los consejos sino, más bien, otro tipo de discursos y recomendaciones asociadas a la 'modernidad' que devienen en la construcción de nuevas subjetividades, las cuales suelen conducir a la observación de que los jóvenes "ya están así como kaxlanes (mestizos)".

En este sentido, por ejemplo, cabe advertir cómo en un ejercicio contrario al modo en que la "voluntad del corazón" es doblegada por las palabras mantal que lo "atraen", la "Voluntad de la cabeza" intenta igualmente ser vencida con recomendaciones que pretenden cautivar la razón y que proceden de esos otros agentes socializadores asociados a la 'modernidad'. Al respecto, mi joven amiga tzotzil Cecilia me contaba la manera en que había iniciado relaciones con su esposo del siguiente modo:

[...] Me habló pero así muy tranquilo, pues yo también le contesté como amigos. Pero pasaron tiempos que como que ya no me veía como amiga, y yo dije: "no, no es posible, yo no quiero". Entonces un día hablé con él muy claramente, que yo no quería nada con él porque pues mi intención es terminar la prepa [preparatoria] y llegar donde he pensado. Entonces así quedamos como amigos. [...] Todo empezó como un juguete desde la escuela porque el profesor también me llevaba mucho con él, nos decía que hacían bonita pareja, porque entonces el profesor se ha dado cuenta. Me preguntaba de por sí si eran nada más amigos o algo más. Y yo le decía que "no va a haber nada más", y me dijo: "pues yo no muy te creo"; "¿y por qué no?"; "porque ya estás enamorada"; "no es cierto, yo no me quiero enamorar". Entonces el profesor me pidió como unos minutos así para platicar qué es lo que quería de por sí: "pues yo lo de terminar mi estudio y la felicidad no pensaba en eso, no, no pensaba en eso"; "no, es que lo importante, bueno, una parte de tu vida debes de tener la felicidad, ¿no?"; "pero nosotros somos muy chiquitos para eso"; "pero es que no es normal que unos amigos llevan tres años y como si nada, ¿no?"; "¿y qué tiene de malo?". Entonces como de por sí él le pidió al profesor que le ayudara, entonces el profesor me dijo: «es que tienes que ir a tal lugar"; "ipor qué?"; "iah!, porque ahí te lo voy a enseñar todo". Y como yo necesitaba ayuda... Y resultó que no encontré al profesor, ahí estaba mi esposo. Pues como era un amigo pues ya me acerqué. Me dijo que si quería yo ser su novia. 
Las respuestas afirmativas, el coqueteo y todo cuanto implica "hablarse entre sí" (incluido ese nuevo estilo de habla más abierto y colmado de "palabras bonitas" en castellano) indican que en la 'modernidad' indígena los ach' chieletik o ach' kuxlejaletik parecieran ser un tipo de personas gobernadas por la "voluntad del corazón" y, por tanto, más ladinas. Cuestión que ha reavivado, otra vez, el debate acerca de la ladinización o mestizaje de la sociedad indígena contemporánea.

Precisamente en un extraordinario trabajo etnográfico sobre las almas tzeltales, propone Pitarch (1996: 123-126) la existencia de un contraste étnico entre corazón y cabeza en donde las voluntades e identidades del corazón se oponen a lo que denomina "la conciencia de la cabeza", señalando cómo las almas radicadas en él poseen rasgos castellanos que dan pistas acerca del carácter étnico de ese otro íntimo. Es más, apunta cómo en un correcto desarrollo cultural de la persona el interior del corazón de alguien, aquello que le viene dado desde antes del nacimiento y formado a priori, produce "un tipo de saber primitivo" relacionado con las emociones que la "Voluntad de la cabeza" ha de transformar. Siendo ilustrativo de este proceso, justamente, la metamorfosis de las palabras en su curso por el cuerpo. Esa "voluntad de la cabeza" asociada al discernimiento y la razón va conformándose con el tiempo mediante el aprendizaje y la experiencia cultural, lo que implica — como se ha visto- la acumulación de palabras mantal dentro de sí. De forma que la variable e innata castellanidad del corazón puede ser modulada culturalmente en un prolongado, continuo y difícil proceso de hacerse por encima de las identidades naturales previas. De ahí su afirmación de que en Cancuc no se nace indígena sino que se alcanza esta identidad en tanto en cuanto se logra, según la edad y la educación, mantener a esos otros "invisibles"; siendo suficiente con que el dominio de la cabeza se debilite para que el interior del corazón se manifieste inmediatamente. Hecho que puede ocurrir en momentos puntuales como durante la borrachera. Entonces:

[...] se pasa de la risa al llanto desconsolado y de nuevo a la risa; se grita, se sienta uno cruzando las piernas, se entra hasta las mismas puertas de una casa sin anunciarse desde la distancia preceptiva, se golpea la puerta con el puño y así. Se pierde la apropiada modestia. Se habla de amor romántico o de desengaños amorosos pese a que en tzeltal no existe un vocabulario preciso para expresar estos sentimientos. Puede ocurrir incluso - como he llegado a ver en alguna ocasión- que un hombre de súbito cariñoso pretenda tocar, abrazar, besar en público a su esposa, exactamente como se sabe que hacen los castellanos (quienes a su vez, en esto al menos, se asemejan a los perros cuando se husmean entre sí). [...] A medida que aumenta la cantidad de alcohol en el cuerpo, los labios pierden dominio sobre el lenguaje y éste comienza a poblarse de palabras en castellano (Pitarch 1996: 126-133).

Actualmente pareciera como si la 'modernidad' (en la figura de diferentes agentes y medios) estuviera debilitando este dominio de la cabeza, e impidiendo la incorporación de las palabras mantal, ampliando a cotidiano y generacional la esencia de este hecho puntual. En un trabajo previo (Neila Boyer 2012) analizaba cómo en este "nuevo vivir" la irrupción de la 'modernidad' y el reacomodo a ella parecieran haber obrado la inversión del protagonismo (y el contraste) de una voluntad regida por la razón —cerebro/cabeza- hacia (o frente a) otra gobernada por el corazón y entendida como efecto de la escolarización. Hecho interpretado como un acercamiento a la identidad mestiza. Esa voluntad orientada por el corazón supone mayor expresivi- 
dad emocional y libertad personal, y equivale gestualmente - $\mathrm{y}$ en términos de carácter - a la idea de sobrepasarse o excederse; gestos que son atribuidos a la pérdida del respeto por parte de las nuevas generaciones, quienes hacen lo que su corazón dice porque éste "es el que manda o es el quien piensa". Apuntaba, además, cómo la máxima expresión de esa pérdida de respeto era la práctica del noviazgo, asociada a la opción por otro modo de vivir, o de querer construir la vida, con más agencia y a partir de nuevas subjetividades modernas. Señalaba, asimismo, que cada una de estas voluntades lleva afiliadas formas de hablar concretas que poseen rasgos étnicos diferenciados y se traducen en concepciones de sí mismos y de la vida específicas. En ese sentido, y respecto al establecimiento de relaciones de pareja, se hacía posible establecer una relación entre la "voluntad de la cabeza" y el pedido de la novia y entre la "voluntad de corazón" y hablarse entre sí donde a cada cual les correspondía un tipo de discurso que era calificado en función de la existencia o no de respeto en sus palabras: de manera que, a grandes rasgos, la ritualidad que detenta el pedido contrasta con la informalidad e irreverencia de una nueva retórica amorosa basada en la apertura y la articulación y emisión de las "palabras bonitas" ${ }^{28}$. Todo ello hace posible averiguar, a través del discurso, qué voluntad gobierna a la persona y calificarla en base a ella, así como augurar el tipo de vida que pretende construir (siguiendo los consejos para el caso de la costumbre o en base a expectativas de futuro en el "nuevo vivir") y los pasos que va a ir dando con este objetivo (Neila Boyer 2012, 2013).

\footnotetext{
${ }^{28}$ A grandes rasgos, y sin intención de simplificar demasiado, el pedido tradicional de la novia, jak'ol, es la forma correcta de establecer relaciones de pareja. Son peticiones formales cargadas de ritualidad. Implica la idea de convencer y tiene que ver con la vergüenza, el sufrimiento y la humillación. Presupone un carácter y una actitud de humildad y respeto. Significa una decisión tomada de forma colectiva, lo que resulta en apoyo familiar y comunitario para la resolución de conflictos maritales. Pone en valor el destino, la asunción de roles impuestos y la construcción social de la vida. Perfila unas relaciones de género basadas en la superioridad masculina. Tiene que ver con la cerrazón emocional, lo que se manifiesta, además, en la inexistencia de un discurso amoroso; sólo se produce una adaptación personal de la pauta cultural para formalizar matrimonios. Por el contrario, "hablarse" - k'opon baik - supone la incorrección y es un modelo asociado con el cambio y la 'modernidad'. Implica la idea de acuerdo, desvergüenza y descaro, lo que en términos de carácter viene notado por el concepto de "cimarrón". Se corresponde con pláticas informales, sin ritualidad ni ceremonia ni tiempos pautados culturalmente. Es producto de decisiones asumidas de manera individual, lo que se materializa, con frecuencia, en cierta soledad familiar a la hora de enfrentar conflictos conyugales. Pone en valor la voluntad, el libre albedrío y la construcción individual de la vida. Existe la percepción de que lleva pareja relaciones de género más equitativas. Supone una apertura emocional y la descripción densa de prácticas individuales inscritas en lo que denominan amor romántico. Para un análisis sobre estos términos ver Laughlin (2007: 90, 137-138, 148). Por otro lado, y al respecto, en 1971 Villa Rojas hacía una observación etnográfica de gran relevancia: «[...] En lo que se refiere al matrimonio, todavía es costumbre, entre los grupos más conservadores, la de ser los padres quienes arreglen el enlace de los hijos, valiéndose de un intermediario que, a veces, es un individuo especializado en ello [...]. La parte más significativa de la petición es expresada en lenguaje grave y ceremonial que subraya el carácter sagrado de los tratos respectivos. [...] En pueblos como Dzitás ya estas cosas se han olvidado y los patrones que se siguen son semejantes a los de la ciudad donde predominan las formas del amor romántico que son del todo ajenas a los modos indígenas. Entre sus observaciones a este respecto, Redfield asienta que: "Es en Dzitás donde se principia a oír eso de que alguien "se enamoró", dicho en tal forma que parece cosa frecuente en el lugar" (1944, p. 260). Aquí los tratos son más bien entre individuos que entre familias" (en Vogt 1971: 373).
} 
En definitiva, podría afirmarse que el emergente discurso amoroso da cuenta - como pocos hechos lo hacen- de las novedosas subjetividades indígenas que se han conformado a partir de la creciente sentimentalización (Shorter 1975) de la sociedad tzotzil contemporánea.

Hasta aquí he tratado de mostrar cómo la inobservancia de la petición ritual, del comedimiento en la expresividad emocional y del apropiado hermetismo en la comunicación son aspectos que de manera privilegiada se ponen de manifiesto en el establecimiento de relaciones de pareja hablándose entre sí. "Hablarse entre sí" se corresponde actualmente, y en muchos casos, con un nuevo estilo de habla (para enamorar) poblado de las que denominan "palabras bonitas"; términos cariñosos que suelen ser emitidos en castellano y que precisamente reflejan estas cuestiones. Un estilo de habla, no lo olvidemos, que en la mentalidad tzotzil supone un habla incompetente e irrespetuosa que lleva aparejada, además, una corporalidad y una moralidad, esto es, un ethos y un gestus diferente. Lo cual ha conducido a la idea de la gente actual como una humanidad distinta de la que se advierte su condición de estar "así como kaxlanes". En este sentido, puede afirmarse que la juventud tzotzil es, en principio, otra gente en tanto en cuanto no sólo emplean más el castellano en determinados contextos asociados a la 'modernidad' y para expresar ciertas experiencias sino que, sobre todo, hacen un uso incorrecto de su lengua (indígena) - por cuanto menor autocontrol emocional, contención comunicativa, etc.- debido a que se encuentran motivados por la "voluntad del corazón"; es decir, hacen lo que su corazón dice y actúan con todo él. Ello les perfila como una gente alejada de ese ideal social de persona cabal e indígena perfilada páginas atrás, cuestión que puede observarse también, tal y como se ha dicho, por la pérdida o el abandono de la apropiada corrección corporal y etiqueta social. De ahí los apelativos con que se ataca a la juventud: toj t'zi' o "demasiado perro", simarron o toj pukuj ("demasiado diablo"), loko/a o coqueto/a, jtoy-ba o alzado/a... La actual abundancia de estas tipologías personales remite a un proceso de construcción de nuevas subjetividades indígenas en la 'modernidad'; unas que han abierto de nuevo el debate acerca de la ladinización o mestizaje de la sociedad tzotzil contemporánea. Debate, por otro lado, que se produce en el seno mismo de su cultura y que la juventud trata de apaciguar efectuando una distinción entre el ser y el aparentar. Esta diferencia surgió en una conversación de domingo, cuando Cecilia fue interrumpida por su hermana menor:

- Cuando alguien se va a ir a estudiar a San Cristóbal ya se pasa, demuestra mucho lo que es de menos - expresó utilizando el término chak chujil en alusión a demostrar exageradamente ser menos indígena-. Aprenden su $t z^{\prime} i$ 'al y algunos ya no quieren regresar. Se ponen zapatos de otro tipo, se compran pantalones como de cholo, su cabello se parece como el del gallo. Así como nosotras como mujeres, se ponen su pantalón, se ponen zapatos con tacón, se pintan las uñas, sus ojos y el cabello. Se maquillan, se depilan.

Me quedé pensando en ambos conceptos y su sentido, que no había entendido del todo. Le pedí a Cecilia una explicación.

—Chak significa dar — me dijo-. Chujil significa sencillo, que no es ni cimarrón, ni alzado, término medio. El término completo significa que demuestra mucho su sencillez.

${ }^{29}$ Chujil es un adjetivo que Laughlin (2007: 52) recoge en su diccionario tzotzil zinacanteco con el significado de chiquito, imbécil, necio. 
Chak chujil es que es una manera como de burla ${ }^{29}$. Es cuando una persona hace cosas que no le quedan, que ni siquiera los kaxlanes lo hacen. Hace cosas que no son sus movimientos; aunque haiga sexys en todo el mundo pero no caminan así como hace... O por su forma de vestir. Hace cosas que no son, cuando haces algo que no es, cuando aparentas... Tz'i' es perro - me explicaba después- pero $t z^{\prime} i$ 'al es su cimarronal. Cha'n tz'i'al es cuando empieza a aprender y después ya actúa.

Con estas palabras mis amistades tzotziles ponían de manifiesto la idea de que aparentar ser menos indígena ocultando la sencillez que les caracteriza no era más que un reflejo de esas "infidelidades transitorias" (Pitarch 2003: 74). Unas que la "modernidad' parece haber reavivado y que hacen del tiempo contemporáneo un "nuevo vivir", ach' kuxlejal. El futuro dirá si estas nuevas subjetividades logran mantenerse dentro de los parámetros culturales de su identidad étnica o no.

\section{BIBLIOGRAFÍA CITADA}

Anales de los cakchiqueles, [en línea], disponible en: <http://americaindigena.com/s8docs.htm>, [consultado el 01/04/2015].

Cámara Barbachano, F. 1946. Monografía sobre los tzeltales de Tenejapa, Microfilm Collection of Manuscripts on Middle American Cultural Anthropology, núm. 5. Chicago: The University of Chicago Library.

Groark, K. P. 2005. Pathogenic emotions: Sentiment, sociality, and sickness among the Tzotzil Maya of San Juan Chamula, Chiapas, Mexico. Ph.D. en Filosofía y Antropología. Los Ángeles: Universidad de California.

Groark, K. P. 2008. "Social opacity and the dynamics of empathic in-sight among the tzotzil maya of Chiapas, Mexico". ETHOS. Journal of the Society for Psychological Anthropology 36(4): 427-448.

Haviland, J. B. 1982. "Inside the Fence; The Social Basic of Privacy in Nabenchauk". Estudios de Cultura Maya, vol. XIV: 323-351. México D.F.: Instituto de Investigaciones Filológicas/Centro de Estudios Mayas, UNAM.

Haviland, J. B. 1984. "Keremcita: Speech relations and social relations in highland Chiapas". Estudios de Cultura Maya, vol. XV: 329-348. México D.F.: Instituto de Investigaciones Filológicas/Centro de Estudios Mayas, UNAM.

Haviland, J. B. 1988. "Minimal Maxims: Cooperation and Natural Conversation in Zinacantán». Mexican Estudies/Estudios Mexicanos, vol. IV, nº. 1: 79-114. The University of California Institute for Mexico and the United States, Universidad Nacional Autónoma de México.

Haviland, J. B y L. K. Haviland. 1983. "Privacy in a Mexican Indian Village", en S. I. Benn y J. Gaus (eds.), Public and Private in Social Life: 341-362. Londres: Croom Helm.

Hermitte, E. 1968. "Movilidad social en una comunidad bicultural". Revista Latinoamericana de Sociología, $\mathrm{n}^{\mathrm{o}}$ 1. Centro de Investigaciones Sociales del Instituto Torcuato Di Tella.

Kaufman, T. 2003. A Preliminary Mayan Etymological Dictionary. Davies: Fundación para el Avance de los Estudios Mesoamericanos (FAMSI).

Laughlin, R. M. 1975. The Great Tzotzil Dictionary of San Lorenzo Zincantan. Washington D.C.: Smithsonian Institution Press.

Laughlin, R. M. 2007. Mol cholobil k'op ta sotz'leb. El gran diccionario tzotzil de San Lorenzo de Zinacantán. México D.F.: CIESAS.

López García, J. 2003. Simbolos en la comida indígena guatemalteca. Una etnografía de la culinaria maya-ch'orti'. Quito: Abya-Yala.

López García, J. 2006. "Cuerpo y sociedad maya ch'orti‘. Representaciones desde la sangre", en B. Muñoz González y J. López García (eds.), Cuerpo y Medicina. Textos y contextos culturales: 385407. Cáceres: CICON ediciones. 
Nash, J. 1970. In the Eyes of the Ancestors. New Haven: Yale University Press.

Neila Boyer, I. 2012. "Ach' kuxlejal (nuevo vivir). Amor, carácter y voluntad en la modernidad tzotzil", en P. Pitarch Ramón y Gemma Orobitg (comp.), Modernidades Indígenas: 279-321. Madrid: Iberoamericana/Vervuert.

Neila Boyer, I. 2013. "Los amores locos de una joven chamula. Simpatías materno-filiales y cambio social". EntreDiversidades, n. 1: 43-85, otoño-invierno. San Cristóbal de las Casas: UNACH.

Neila Boyer, I. 2015a. "Toj jamal ye'. La excesiva apertura personal y social en el "nuevo vivir" tzotzil de Chiapas". Estudios de Cultura Maya (en prensa).

Neila Boyer, I. 2015b. "La sociedad tzotzil en la industria del ruido". Mexican Studies/Estudios Mexicanos, (en dictamen).

Neila Boyer, I. 2015c. "El lenguaje informal del amor en el "nuevo vivir" tzotzil: del silencio a las "palabras bonitas". AIBR, (en dictamen).

Paoli, A. 2003. Educación, autonomía y lekil kuxlejal: aproximaciones sociolingüisticas a la sabiduría de los tzeltales. México D.F.: UAM.

Pitarch Ramón, P. 1996. Ch'ulel: una etnografía de las almas tzeltales. México D.F.: FCE.

Pitarch Ramón, P. 2000a. "El cuerpo y el gesto. Notas sobre el "arte" tzeltal". Journal de la Societé Suisse des Americanistes 64: 43-52.

Pitarch Ramón, P. 2000b. "Conjeturas sobre la identidad de los santos tzeltales". Journal de la Société des Américanistes 86: 129-148.

Pitarch Ramón, P. 2001. "El laberinto de la traducción", en P. Pitarch y J. López García (eds.), Los derechos humanos en tierras mayas. Politica, representaciones y moralidad: 127-161. Madrid: Sociedad Española de Estudios Mayas.

Pitarch Ramón, P. 2003. "Infidelidades indígenas". Revista de Occidente 269: 60-75.

Pitarch Ramón, P. 2006. "La conversión de los cuerpos. Singularidades de las identificaciones religiosas indígenas", en B. Muñoz González y J. López García (coord.), Cuerpo y medicina. Textos y contextos culturales: 341-358. Cáceres: CICON ediciones.

Pitarch Ramón, P. 2013. La cara oculta del pliegue. Ensayos de antropología indígena. México D.F.: CONACULTA/Artes de México.

Recinos, A. 1999. Popol Vuh. Las antiguas historias del Quiché. México D.F.: FCE.

Ruz, M. H. 1985. Copanaguastla en un espejo. Un pueblo tzeldal en el virreinato. San Cristóbal de las Casas: Centro de Estudios Indígenas/UNACH.

Shorter, E. 1975. The Making of the Modern Family. New York: Basic Books.

Stross, B. 1973. "El contexto sociocultural en la adquisición de la lengua Tzetzal". Estudios de Cultura Maya 9: 257-301.

Tedlock, D. 1993. Breath on the Mirror: Mythic Voices and Visions of the Living Maya. San Francisco: Harper \& Collins.

Villa Rojas, A. 1985. Estudios etnológicos. Los mayas. México: UNAM.

Vogt, E. Z. y A. Ruz L. 1971. Desarrollo Cultural de los mayas. México: UNAM.

Fecha de recepción: 3 de febrero de 2015

Fecha de aceptación: 25 de febrero de 2015 